Hope College

Hope College Digital Commons

Faculty Publications

$3-27-2017$

\title{
Stress Buffer or Identity Threat?: Negative Media Portrayal, Public and Private Religious Involvement, and Mental Health in a National Sample of US Adults
}

\author{
Samuel Stroope \\ Louisiana State University \\ Mark H. Walker \\ Louisiana State University \\ Aaron B. Franzen \\ franzen@hope.edu, franzen@hope.edu
}

Follow this and additional works at: https://digitalcommons.hope.edu/faculty_publications

Part of the Medicine and Health Commons

\section{Recommended Citation}

Repository citation: Stroope, Samuel; Walker, Mark H.; and Franzen, Aaron B., "Stress Buffer or Identity Threat?: Negative Media Portrayal, Public and Private Religious Involvement, and Mental Health in a National Sample of US Adults" (2017). Faculty Publications. Paper 1435.

https://digitalcommons.hope.edu/faculty_publications/1435

Published in: Society and Mental Health, March 27, 2017, pages 1-20. Copyright @ 2017 SAGE Publications.

This Article is brought to you for free and open access by Hope College Digital Commons. It has been accepted for inclusion in Faculty Publications by an authorized administrator of Hope College Digital Commons. For more information, please contact digitalcommons@hope.edu. 
Stress Buffer or Identity Threat?: Negative Media Portrayal, Public and Private Religious Involvement, and Mental Health in a National Sample of US Adults

\author{
Samuel Stroope* \\ Department of Sociology \\ Louisiana State University \\ Mark H. Walker \\ Department of Sociology \\ Louisiana State University
}

Aaron B. Franzen

Department of Sociology and Social Work

Hope College

*** Accepted and forthcoming in Society and Mental Health ***

*Direct correspondence to Samuel Stroope, Department of Sociology, Louisiana State University, 126 Stubbs Hall, Baton Rouge, LA, 70803. Tel.: 225-578-1645. Fax: 225-578-5102. Email: sstroope@lsu.edu.

Acknowledgements: Thanks to Heather Rackin and members of the LSU sociology writing group for comments on an earlier draft of this paper. 


\title{
Stress Buffer or Identity Threat?: Negative Media Portrayal, Public and Private Religious Involvement, and Mental Health in a National Sample of US Adults
}

\author{
ABSTRACT \\ Guided by the stress process tradition, complex links between religion and mental health have \\ received growing attention from researchers. This study gauges individuals’ public and private \\ religiosity, uses a novel measure of environmental stress—-negative media portrayal of religion- \\ and presents two divergent hypotheses: (1) religiosity as stress-exacerbating attachment to \\ valued identities producing mental health vulnerability to threat; and (2) religiosity as stress- \\ buffering social-psychological resource. To assess these hypotheses, we analyze three mental \\ health outcomes (generalized anxiety, social anxiety, and general mental health problems) in \\ national U.S. data from $2010(N=1,714)$. Our findings align with the stress-buffering \\ perspective. Results show that individuals low in public and private religiosity tend to have \\ worse mental health with greater negative media portrayal. High public or private religiosity \\ tends to nullify the relationship between negative media portrayal and mental health.
}


How do environmental threats to religious beliefs impact mental health? Social psychological research on identity processes suggest that role- and group-based identities are beneficial for mental health because they provide individuals with a sense of belonging and a meaningful, guided existence (Thoits 1983, 1991, 2003). Based on a long line of research documenting the relationship between environmental threats to identity and distress, identity theory (Stryker 1980; Burke and Stets 2009) suggests that environmental threats to valued identities should be especially distressing (Thoits 1991; Stryker 1987). Social psychologists have long noted the importance of religion for the self-concept (Stryker and Serpe 1982). Negative media portrayal of a person's religious faith is a specific case of environmental threat and a stressor that is particularly important for the many Americans with ties to religious identities, beliefs, and communities. Indeed, Americans adhere to religious practice and belief at relatively high rates compared to other rich nations. Religious congregations are the most common form of voluntary association for Americans and ninety-six percent of Americans report some degree of belief in God (Froese and Bader 2010). Thus, understanding the role of religion for personal well-being is of broad importance in American society. A growing body of research finds that religious involvement generally has beneficial or stress-buffering associations with mental health (Koenig, King, and Carson 2012; Schieman, Bierman, and Ellison 2013). This contemporary research stands in contrast to earlier literature which viewed religion as a source or type of mental health problem (Freud 1928). A resurgence of recent studies, however, show that aspects of religion may also have detrimental or stress-exacerbating effects on a range of mental health outcomes (Ellison and Lee 2010; Krause and Wulff 2004; Lim 2015; Pargament et al. 2004; Uecker et al. 2015). 
Research on the deleterious effects of religion on mental health has typically examined sources of noxious impact internal to religion (e.g., spiritual struggles, congregational conflict, spiritual abuse) (Exline 2002; Hill and Cobb 2011). Little research has examined impacts on religious individuals external to—but necessarily derived from—religion. Within this vein, relatively little is understood about the links between mental health and individuals' perception of these external sources, such as negative portrayal of one's faith in society. These gaps in knowledge are surprising given the importance of social stress (e.g., stigma, discrimination) for mental health (Link and Phelan 2001; Pearlin 1989), the longstanding importance of religion for the self-concept (e.g., Stryker and Serpe 1982; Walker and Lynn 2013), and the prominence of religious tension with society in social scientific studies of religion (Emerson and Hartman 2006; Stark and Finke 2000).

Studies at the intersection of religion and mental health suggest that relationships between stress and mental health are frequently contingent upon individuals' religiousness. For example, recent research finds that the negative effects of spiritual struggles on mental health are greater for more highly religious individuals (e.g., Ellison et al. 2013). Based on this background, one hypothesis would suggest that more religiously involved persons will have greater mental health problems when encountering the threat of negative media portrayal of their faith. A second hypothesis is prompted by studies showing that deleterious effects on mental health from stressors are ameliorated by individuals’ social and psychological resources (Wheaton 1985). Religious involvement often acts as an important buffering resource for individuals experiencing stressors such as racial discrimination or neighborhood disadvantage (Acevedo, Ellison, and $\mathrm{Xu}$ 2014; Bierman 2006). If religious involvement can serve as a buffer to these secular stressors, it 
might also be effective in buffering negative mental health effects of religious tension with the sociocultural environment and related stress—a hypothesis not previously tested.

We assess these hypotheses and address gaps at the above intersections by using structural equation modeling to examine three mental health outcomes in a national sample of American adults $(N=1,714)$. We advance prior research by utilizing a novel measure of environmental stress related to a major social institution in society—offense at television media portrayal of one's religious faith. This application of media portrayal as an environmental threat rather than focusing exclusively on reflected appraisals constitutes an expansion of identity theory. Our findings add to current thinking around processes connecting environmental threats, religious commitment, and mental health.

Below, we begin by discussing media portrayal of religion, and provide rationale for two divergent hypotheses: (1) religious involvement as attachment to valued roles and personal identity that produce vulnerability to the threat of negative media portrayal; and (2) religious involvement as a social and psychological resource that buffers the effects of negative media portrayal.

\section{BACKGROUND}

\section{Media portrayal of religion and mental health}

Stressful environmental inputs can harm mental well-being by disrupting social roles and salient identities and producing a sense of threat for individuals (Burke 1991; Thoits 1992, 2012). Negative media portrayal of a person's religious faith is a specific case of environmental threat and a stressor that is especially important for the many Americans for whom religion is central to the self-concept (Stryker and Serpe 1982). For many people, television viewing is a 
significant point of contact with broader society. The mass media is a prominent social institution and television is particularly ubiquitous and an important part of social life serving various purposes including disseminating cultural views and functioning as a public forum (Wuthnow 1987). Religion is a topic discussed and portrayed, not only in news media (Thomson, Park, and Kendall 2014), but across a wide range of television programming (Bader, Mencken, and Baker 2010). Within this programming, discussions of religion on television can frequently be negative (Kerr 2003) and some evidence suggests that national media elite are more secular than the general public and may be biased in their treatment of religion (for a review, see Hoover 2005). Indeed, a substantial portion of the public perceives a bias against religion—in a recent national survey, one third of Americans reported that their religious views are often ridiculed by the media. ${ }^{1}$

Perceptions of television portrayals of religion are an important source of environmental threat to one's faith because people may be relatively shielded from such threats in everyday face-to-face interactions. One source of this insulation comes from the tendency for people to have religiously similar social ties (Baker and Smith 2009). Data from the 2006 General Social Survey indicate that the degree of reported social separation based on religious participation is similar to levels of social separation based on race (DiPrete et al. 2011). When social interaction in friendships or other contexts occur between religious adherents and non-adherents, religious "beliefs ... are usually of little concern” and open animosity toward religion is unlikely to be explicitly expressed (Vargas and Loveland 2011:726). Thus, religious individuals may not encounter frequent negativity toward their faith in interpersonal interactions, but may well do so when watching television.

\footnotetext{
${ }^{1}$ Author's calculations from Baylor Religion Survey-2.
} 
Religion's associations with well-being come from the ability of religion to provide social integration, existential security, identity, sense of meaning, and continuity in life, among other resources (Berger 1967; Ellison 1991; Idler, Hogue, and Scheib 2010; Inglehart 2010; Stryker and Serpe 1982). It is precisely because religion provides such resources for many people that negative portrayals of faith can be a threat to the potency and stability of a healthpromoting resource and ultimately stress-inducing. Several mechanisms linking perceived discrimination and mental health are relevant to negative portrayals of religion on television. Certain forms of television viewing are associated with elevated levels of fear (Glassner 2010). Perceiving negativity toward religion on television may increase fear regarding broader society's animosity toward one's faith. In other words, viewers may feel that negativity toward one's faith expressed on television reflect a broader hostility in the general public. Derisory comments and slights toward one's religious faith on television may also lead to anger-inducing aggravations and a variety of other negative emotions.

\section{Religion as vulnerability to stress-exacerbation: The identity threat hypothesis}

The deleterious effects on mental health of negative media portrayals are unlikely to be the same for everyone and stress-exacerbation may occur for more highly religious individuals. Researchers in identity theory (Burke and Stets 2009; Stryker 1980) have long acknowledged the importance of religion for the self-concept (e.g., Stryker and Serpe 1982; Walker and Lynn 2013). According to identity theory (IT), identities are important for mental health because they provide individuals with a meaningful, guided existence, which is thought to reduce the existential uncertainty that is inherent in our complex social reality (Thoits 1983). Indeed, religious identities may be particularly important for reducing existential uncertainty, given most 
religions' explicit focus on questions of metaphysics, ethics, and meaning in life (Froese 2016; Stroope, Draper, and Whitehead 2013).

Based on the assumption that individuals utilize structurally-based identities to guide behavior, IT proposes a perceptual control model of behavior, which suggests that meaningful social behavior is directed toward verifying self-held identity meanings (Burke 1991; Burke and Stets 2009). That is, individuals have a sense of who they are as an occupant of a given social position or social role (e.g., “as a Christian, I am moral and caring”) and they compare this identity standard to their perceptions of environmental feedback (e.g., "people seem to think that I am hypocritical and selfish”). To the extent that perceptions of environmental feedback (e.g., reflected appraisals) match one’s identity standard, identity verification is accomplished and the individual will experience positive emotions. Conversely, if environmental feedback does not match one's identity standard, identity verification is blocked and the individual will experience negative emotions, such as sadness, anger, and guilt (Burke and Stets 2009). Indeed, IT research has documented a consistent relationship between identity non-verification and negative mental health outcomes such as reduced self-esteem (Cast and Burke 2002; Stets and Burke 2014a), increased distress (Burke and Harrod 2005), and negative emotions (Stets and Burke 2014b). Building on the link between the identity verification process and emotional outcomes, IT scholars have further argued that the strength of the emotional response to identity (non)verification should depend on how important the identity is to one's overall self-concept (Burke 1991; Stryker 1987). That is, environmental feedback that threatens highly salient identities should be more detrimental to mental health and emotional well-being than environmental threats to identities that are unimportant to an individual's self-concept. Indeed, recent research on religious doubt finds that persons more heavily invested in their religious 
identity suffer the most when experiencing higher levels of doubt (Ellison et al. 2013). Although the identity theory model has generally been applied to interpersonal interaction, we believe it is appropriate to extend the theory's conception of "environmental feedback" to include media portrayal of one's religion because these media portrayals constitute "self-relevant meanings" in one's social environment that matter for the self-concept. Specifically, in our view, media portrayals act as identity threats in much the same way that face-to-face social encounters do. Thus, the identity threat hypothesis suggests that the relationship between negative media portrayal of religion and lower psychological well-being will be weaker for people with lower levels of religious involvement and stronger for people with higher levels of religious involvement.

Distinct dimensions of religion are known to operate differently in relation to mental health, thus researchers increasingly treat different dimensions of religion separately (Koenig et al. 2012). In our study, private and public religiosity represent different dimensions of potentially vulnerable aspects of one's religiousness and so we assess their exacerbation of media portrayal effects independently. For example, individuals immersed in religious thoughts and teachings through private prayer and scripture reading may find negative media portrayals of their faith particularly distressing because of the cognitive discordance and potential shame produced. For those frequently involved in public religious services, media portrayal may result in threats to valued roles occupied in their faith community (e.g., deacon, Sunday school teacher, spiritual friend, faithful volunteer) and assaults to central facets of their identity.

\section{Religion as a social and psychological resource: The stress-buffering hypothesis}


While the stress-exacerbation approach outlined above highlights religion as a source of vulnerability, other research suggests that religiosity can act as a buffer against the negative mental health effects of stressors (e.g., discrimination and financial strain) (Bradshaw and Ellison 2010; Ellison, Musick, and Henderson 2008). If religious resources and religious coping can reduce the impact of such secular stressors, religion may aid in lessening stress associated with negative media portrayal of one’s faith. Below, we outline several ways religious buffering operates. First, we discuss how religion is used in the framing and appraisal of stressors and then we turn to a range of supports provided by public and private religious involvement.

Religion can aid psychological well-being in the face of a stressor through a two-stage appraisal process: (1) primary appraisal and (2) secondary appraisal of the stressor (Ellison and Henderson 2011; Folkman and Moskowitz 2004). Primary appraisal involves evaluating or defining the nature of the stressor and what it means for the individual's fundamental sense of self and overall outlook on life. For example, private religious practices such as prayer and scripture reading can help people see a stressor in reassuring ways, as part of a larger purpose, as a crucible for spiritual growth, or as a threat rendered benign to more essential aspects of the self in relation to God (Henderson and Ellison 2014; Idler 1995; Pargament, Koenig, and Perez 2000). Secondary appraisal involves assessing potential resources at hand which may be used to work out the situation or cope with its impact. This mode of appraisal draws on religion in important ways when people consider the practical or emotional support that is anticipated to be available to them in their religious community, beliefs, and practices (Ellison et al. 2009; Pieper and Van Uden 2005). For example, if a media criticism is directed at the historical accuracy of the Bible, a conservative church member may mentally resolve this challenge by assuming that a fellow congregant skilled in apologetics probably has a good response to the criticism. 
Importantly, people need not actually have or use these resources for them to be helpful in appraising a stressor. Indeed, the anticipation of support can be more ameliorative than the actual use of support (Edgell, Tranby, and Mather 2013).

Scholars also suggest that congregational attendance and private religious practices lead to psychological well-being through providing opportunities for religious, emotional, social, and instrumental support (Ellison et al. 2009; Krause 2008; Nooney and Woodrum 2002). One important way that congregations are effective in providing such supports is by connecting people to a community larger than their immediate set of personal relationships—a community which can socially embed and ratify religious values under a canopy of shared beliefs, what Berger (1967:45) famously referred to as a "plausibility structure.” Negative social experiences significantly contribute to religious doubt, so it makes sense that positive social experiences through participation in a religious community of likeminded people should protect against the health-eroding effects of religious doubt (Krause and Ellison 2009). Additionally, through private devotional practices such as prayer or meditation on scriptures, individuals can engage in an internal dialogue and take the role of the other, including God, saints, or other religious conversation partners (Pollner 1989). Such practices mentally recirculate and reinforce religious experiences and social interactions, thereby strengthening religious belief and lessening doubt (Collins 2010). In short, "religious ideation is grounded in religious activity” (Berger 1967:40).

Beyond addressing religious doubt, individuals can also air their feelings of distress, anger, or perceived discrimination in private devotions or to fellow churchgoers and receive not only general emotional support, but also affirmation of such feelings placed in the context of a larger reassuring religious narrative. Religious symbolism and beliefs reinforced through religious involvement "provide an interpretive framework through which individuals can make 
sense of everyday reality" (Ellison 1991:89). Because congregants often share not only religious beliefs but also ideas and practices regarding support, fellow congregants may provide especially effective support to each other (Ellison and George 1994). Whereas friends outside the congregation may not understand why negative media portrayal of religion is unsettling, congregational friends can understand and validate a person's feelings.

Religious involvement can provide other protective psychological resources. While negative television portrayal of a person's faith may lead to lower self-esteem, a person's selfesteem can be recalibrated in private devotions where she is reminded of her status as a child of God or through frequent attendance at a congregation where she is respected and valued by members (Schieman, Bierman, and Ellison 2010). Further, attachment theory research finds that secure forms of attachment are linked to psychological well-being. Work based on attachment theory argues that devotional practices can cultivate a sense of deepening a secure attachment with God—a "safe haven" in the face of perceived threats (Bradshaw, Ellison, and Marcum 2010; Ellison et al. 2014; Rowatt and Kirkpatrick 2002). Forgiveness is also taught in many religious communities and has been found to be a beneficial psychological resource (Sternthal et al. 2012). If stressful media portrayal causes anger and negative emotions, religiously-supported forgiveness — either with the help of fellow believers or in private devotions — may aid in letting go of distressing feelings (Krause and Ellison 2003).

Thus in contrast to the identity threat hypothesis, the stress buffering hypothesis expects that the relationship between greater negative media portrayal of faith and greater mental health problems will be stronger for people with lower levels of public and private religious involvement and weaker for people with higher levels of involvement.

\section{DATA AND METHODS}


The data used for this study come from the third wave of the Baylor Religion Survey (BRS), the only wave in which the necessary study measures are available (no other waves contain the mental health or media items). The BRS is a repeated cross-sectional random national sample of US adults collected by the Gallup Organization in 2010. Following the mixed-mode methodology of prior waves of the BRS (Bader, Mencken, and Froese 2007), participant selection began with random digit dialing and the assenting participants received the self-administered survey through the mail. Of the 2,556 surveys mailed, 1,714 were returned by participants for a contact-to-completion response rate of 67.1\% (overall response rate: $24.5 \%$ ). While a national sample, the BRS differs from the overall national population in that the percentage white is higher (92.6\% weighted and 94.8\% unweighted). Despite variability between the racial composition of the sample and that of the overall populations, our regression coefficients should remain unbiased since race is statistically controlled in all models (Winship and Radbill 1994). The BRS is the only dataset we are aware of that combines religious involvement variables, media portrayal of religion measures, and mental health scales.

\section{Analytic Method}

Feeling that one's religious beliefs are negatively portrayed on television is a general perception that can be more or less strongly related to different television genres. Structural equation modeling allows us to distill and model only this general perception. The same is true for mental health outcomes - we can ask a series of questions highlighting the various manifestations of an underlying problem, and model only the disorder as a latent variable instead of each manifestation of the disorder. In this way, structural equation modeling allows us to model the effect that a general perception of negative portrayal of religion on television programs has on a respondent's mental health (indicated by mental health experiences) (see 
Figure 1). Scales or indexes could also be used, but latent variables are advantageous in their handling of measurement error in comparison. For latent variable analysis, we used the lavaan package in $R$. Missing values were handled using multiple imputation. Lavaan uses a mean and variance-adjusted weighted least squares estimator for categorical data, which provides robust standard errors as well as both a mean and variance-adjusted test statistic. As lavaan does not have the latent moderated structural equation approach at this time, the double mean-centered product indicator approach is used here (Lin et al. 2010). In order to assess model fit, we show the root mean square error of approximation (RMSEA), standardized root mean square residual (SRMR), both indicating better model fit as they approach zero, as well as the comparative fit index (CFI) and McDonald's noncentrality index (Mc), which reflect better model fit as they approach one. Fit statistics indicate that our models have good fit. ${ }^{2}$

$$
\text { [Insert Figure } 1 \text { about here] }
$$

\section{Measures}

\section{Dependent Variables}

Table 1 presents question wording, standardized factor loadings, and omega scores for focal variables. We focus on three latent mental health outcomes: general anxiety, social anxiety, and general mental health problems. To indicate latent variable reliability, we used McDonald's omega. Cronbach’s Alpha scores are based on item correlations and assume equal item contribution and error (tau) equivalence. Omega, however, is based on factor loadings allowing for exclusion of dissimilar item contributions and is preferred in most circumstances (Zinbarg et al. 2005). When tau equivalence is present, omega is equal to alpha.

\section{[Insert Table 1 about here]}

\footnotetext{
${ }^{2}$ Fit statistics are given in the bottom panel of tables 3 and 4. Hu and Bentler (1999) argue model fit is acceptable when either the $\mathrm{CFI} \geq .96$ and $\mathrm{SRMR} \leq .09$ or $\mathrm{SRMR} \leq .09$ and $\mathrm{RMSEA} \leq .06$. As recent work questions the finality of this joint criteria, we also include Mc which is useful with larger sample sizes (Sivo et al. 2006).
} 


\section{Interaction Terms}

The key independent measure-negative media portrayal—is a latent variable reflecting respondents' feeling their religious beliefs have been offended by comments made across a range of television programs (1=yes, else 0$)$ : crime dramas (31.3\%), medical dramas (31.4\%), reality TV (36.2\%), comedic “news” (37.3\%), comedic sitcoms (33.8\%), cable news (39.1\%), and evening news programs (29.6\%). Sixty-five percent of respondents had been offended by at least one type of television program. Given latent variables' lack of inherent metrics, we used the effects-coding approach for interpretability in Figures 2 - 3, which constrains latent variable loadings to an average of 1 aiding the interpretation of the y-axis, but a standardized metric in Tables 3 and 4 (Beaujean 2014).

Media portrayal was then included in two sets of interactions: (1) a public religiosity measure, "how often do you attend religious services at a place of worship" with responses ranging from never (0) to several times a week (8); and (2) private religiosity - a composite of two standardized questions, “outside of attending religious services, about how often do you spend time alone reading the Bible, Koran, Torah or other sacred book” with responses ranging from never (0) to several times a week or more (8), and "about how often do you spend time alone praying outside of religious services” with responses ranging from never (0) to several times per day (5). We used semTools in $R$ to create double mean-centered variables with an allpairs configuration for interaction terms. Double mean-centered interactions are preferred to mean-centered approaches and are created by first mean-centering observed variables to reduce multicollinearity, and second forming the interactions and re-centering them eliminating the need to include the mean structure (Lin et al. 2010). The all-pairs product indicator strategy outperforms the matched-pair approach (Marsh, Wen, and Hau 2004) as models still converge 
and there is less variation in estimates and standard error bias between the possible product indicator configurations with the matched-pair approach (Foldnes and Hagtvet 2014).

\section{Control Variables}

As controls we include television exposure: “on an average day, about how many hours per day do you watch television” with responses of $<1$ hour per day, 1 - 3 hours per day, $4-7$ hours per day, 8 - 10 hours per day, and > 10 hours per day, a modification of the RELTRAD religious affiliation scheme: evangelical Protestant (referent), Mainline Protestant, Catholic, Jewish, other, and none (Dougherty, Johnson, and Polson 2007; Sherkat 2014; Steensland et al. $2000)^{3}$, respondent's age (continuous), race (white), sex (female $=1$ ), urbanicity (urban $=1$ ), southern residence (South $=1$ ), marital status (married $=1$ ), college education (bachelor's degree $=1$ ), employment status (employed $=1$ ), and income (series of dummies with $\$ 35,000-\$ 50,000$ as referent).

\section{[Insert Table 2 here]}

\section{RESULTS}

Models 1 and 5 in Table 3 show that the main effects of public religiosity are significant and inversely associated with generalized anxiety and general mental health problems. An inverse but nonsignificant relationship between public religiosity and social anxiety is observed in Model 3. The main effects of media portrayal on mental health outcomes do not reach statistical significance. The interaction between public religiosity and negative media portrayal (Table 3, Models 2, 4, and 6) is significant in relation to two of the three mental health outcomes: general anxiety and general mental health problems. As seen in Figure 2, in both instances, the relationship between media portrayal and these health outcomes is moderated by public

\footnotetext{
${ }^{3}$ Results are not meaningfully changed when a separate category for African American Protestants is used.
} 
religiosity such that the impact of media portrayal on mental health problems becomes less pronounced at higher levels of public religiosity. For low-public religiosity individuals (2 standard deviations below mean religiosity), there is a positive (detrimental) association between media portrayal and mental health problems, but the magnitude of this effect steadily decreases at higher levels of public religiosity. For individuals with high public religiosity (1 and 2 standard deviations above the mean), the impact of media portrayal is not statistically different from zero, suggesting that religious attendance is capable of nullifying the negative effects of negative media portrayals on mental health. These findings provide support for the stressbuffering hypothesis.

\section{[Insert Tables 3]}

[Insert Figure 2 about here]

For the main effects in Table 4 (Models 1, 3, and 5), we see that there is a nonsignificant inverse relationship between private religiosity and generalized anxiety and social anxiety and a nonsignificant positive relationship with general mental health problems. The main effects of media portrayal on mental health are positive for all three outcomes but only statistically significant in the case of social anxiety. ${ }^{4}$ The interaction between private religiosity and media portrayal (Table 4, Models 2, 4, and 6) is significant in relation to all three mental health outcomes. Figure 3 shows these interactive relationships. There is a similar pattern to that seen in the case of public religiosity. For all three outcomes, the relationship between media portrayal and mental health problems is significantly moderated by private religiosity. For moderate-to-

\footnotetext{
${ }^{4}$ This pattern of results suggests that the heterogeneity in the global effect of negative media portrayals masks the effects of media portrayals at average and below average levels of religiosity. That is, since individuals with higher than average levels of public and private religiosity (+1STDV and +2STDV) display a negative (but non-significant) relationship between negative portrayals and mental health problems (see Figures 2 and 3), the slope of the global mean is effectively pulled downward. By allowing the effect of negative media portrayals to differ by level of religiosity, we show that negative media portrayals are, in fact, associated with negative mental heath outcomes for certain subgroups (i.e., individuals with average and low levels of religiosity).
} 
low-private religiosity individuals (mean religiosity, 1, and 2 standard deviations below mean religiosity), there is a positive (detrimental) association between media portrayal and all three mental health outcomes. However, as in the case of public religiosity, individuals with high levels of private religious participation seem to be unaffected by negative media portrayals with respect to our mental health outcomes (i.e., the slopes are not statistically different from zero), providing additional support for the stress-buffering hypothesis.

[Insert Table 4 here]

[Insert Figure 3 about here]

\section{DISCUSSION}

The findings of this study advance our understanding of the role of potentially stressful environmental elements in the religion-health connection and how inputs to mental health are contingent upon religious involvement. Using a national sample of U.S. adults, we employ a novel measure of environmental stress—-negative portrayal of religion in television mediaespecially germane to the more than 95\% of Americans who report religious belief or practice (Froese and Bader 2010). In particular, we examine how the effects of media portrayal of religion on mental health may differ for less religious individuals compared to devout individuals. In general, our findings provide support for the stress-buffering hypothesis over the identity threat hypothesis. Consistent with the stress-buffering hypothesis, we find that the positive impact of negative media portrayals on mental health problems is reduced as religious participation increases (with the exception of social anxiety in the public religiosity models). A novel contribution of this study is to examine the relationship between an important environmental threat toward religion—negative media portrayal—and mental health. While this 
is a first step in a potentially fruitful avenue of research, our findings do suggest initial insights and questions when compared to prior research.

First, we find that public religiosity is inversely associated with two of our three mental health problem outcomes and private religiosity has no significant association with mental health. These main effect results align with previous research showing consistent associations between public religious involvement and desirable mental health outcomes and nonsignificant or mixed associations between private religiosity and mental health (Schieman et al. 2013). Turning to our focal results, contrary to the identity threat hypothesis, the relationship between negative media portrayal and mental health problems does not become more strongly positive (i.e., more detrimental) at higher levels of religiosity. Our findings suggest that media portrayal is associated with greater mental health problems for individuals with low levels of religiosity and media portrayal is not associated with mental health at high levels of religiosity. These findings align with the stress buffering perspective and are broadly resonant with a growing body of research on the stress-buffering potential of religious involvement (Ellison and Henderson 2011). Stress buffers are generally thought to reduce the negative impact of a stressor on mental health outcomes, which our results bear out in the case of both public and private religiosity. Indeed, religious participation not only reduces the deleterious effect of negative media portrayals, but it appears to nullify the effect of media portrayals for the highly religious. Thus, our results may suggest that only individuals with low-to-moderate levels of religiosity are "at risk" to the negative mental health consequences of negative media portrayals of religion.

Consistent with identity theory, recent research on spiritual struggles (e.g., religious doubt) finds that persons more heavily invested in their religious identity suffer the most when experiencing higher levels of religious doubt (Ellison et al. 2013). Contrastingly, in our analyses, 
it is those least invested in religion (measured as low participation) whose mental health is most vulnerable. That our results show a pattern opposite to identity theory and prior research on religious doubt suggests that mechanisms linking our measure of religious stress and mental health may have little to do with religious doubt. The offense people experience at negative media portrayal of their faith may have more to do with feelings of unfairness toward religion, sacrilegious content, or other programming perceived to be especially threatening to persons less connected to the social and psychological resources within active religious involvement. It may also be that highly religious people have a higher threshold for what they interpret as an actual threat to their religious beliefs. This observation is resonant with research on intrinsic religion, defined as religiosity primarily motivated by serving and knowing the divine (Allport 1950). Our results align with the work of Schieman (2008) who found that belief in divine engagement in one's life is associated with low personal sense of control for persons with low commitment to the religious role, but not for persons with high commitment to the religious role. Other recent research also shows especially unfavorable outcomes for similar individuals with low levels of religious involvement but who are nonetheless somewhat religious (Lim 2015; Pearce and Davis 2006; Uecker and Stokes 2008). It is possible that these individuals' religious sentiments become frustrated when disconnected from supportive religious communities or regular practices. Taken together with the results of the current study, this set of findings points to an area in need of future research and theoretical consideration.

It is worth noting that our findings were not entirely consistent across all outcomes. While private religiosity moderated media portrayal associations with all three mental health outcomes and public religiosity did so for two, we did not observe an interplay between media portrayal, public religiosity, and social anxiety. In the case of private religiosity, we found that 
media portrayal was associated with greater social anxiety among moderate-to-low private religiosity individuals. For high-private religiosity individuals, the relationship between media portrayal and social anxiety was nullified. Speculatively, because private religiosity may provide complex resources to mitigate the threat of rejection by others concomitant with social anxiety, the lack of these resources may place individuals in an especially vulnerable position in relation to negative media portrayal of one's faith. Private religious practice (e.g., scripture reading) can remove the sting of social threats to the self by reassuring individuals that though their religion may have low status in the eyes of some, they possess a secure spiritual status (e.g., a child of God). Practices such as scripture reading may also help remind individuals that threats from nonadherents should not be surprising or necessarily devastating (e.g., "people have long had troubles for their faith”). In short, scripture reading may help people neutralize or reframe such threats by placing themselves within a divine narrative or plan. The meditative benefits of religious reading may in reality be difficult to distinguish from those of prayer, often practiced alongside scripture reading. Prayer may help individuals feel that they have a close and supportive relationship with the divine, which can be especially ameliorative and purpose-giving when coupled with loving and caring divine images (Bradshaw et al. 2010; Stroope et al. 2013). Overall, private religiosity, as a form of interior dialogue (Collins 2010), may be effective in buffering influences on mental health through interpretive processes of benevolent reframing and appraisal of the stressor. In short, persons low in these resources stemming from private religiosity are more vulnerable to associating media portrayals with broader social rejection.

Although our pattern of results do not support the identity threat hypothesis, this should not be taken as direct evidence against the identity theory (IT) model. As discussed, our application of IT to the relationship between religious involvement, negative media portrayal, 
and mental health constitutes an expansion of IT to include media portrayal (rather than focusing exclusively on reflected appraisals). Further, it is unclear how individuals interpret negative media portrayal of their faith, other than feeling offended. Our results show that at high levels of religiosity, media portrayal has no significant association with mental health problems. It might be that the experience of negative portrayal is readily assimilated by the highly religious, for whom it can be interpreted in a purpose-giving light, as a crucible for personal spiritual growth (Foley 1988), thus diminishing its negative effects. Religious individuals might also interpret negative media portrayal of religion not as identity threat, but rather as consistent with religious narratives that highlight distinctions between sacred and profane, pure and impure, holy and worldly, and so on (Douglas 1966; Durkheim 1912). For those immersed in the social life of their religion, tension with the sociocultural environment can be interpreted as confirmation of faithfulness, thus bolstering a sense of purpose, self-esteem, status, and sense of belonging in the group (Smith et al. 1998; Stark and Finke 2000; Stroope 2011). Thus, the effects of negative media portrayal may be reduced or completely offset for the highly religious who have stronger symbolic boundaries between themselves and non-believers—-boundaries which strengthen cohesion, solidarity, and shared identity among coreligionists (Iannaccone 1994; Smith et al. 1998).

Our results may contribute to identity theory by highlighting the complexity of the relationship between environmental threats to an identity, identity salience, social and psychological resources available in role-domains, and mental health. Indeed, although IT suggests that threats to highly salient identities should be especially problematic for mental health, the empirical research examining this link has been mixed (Thoits 1992, 2013). Our findings point to two potential sources that may confound this relationship: 1) the social, cultural, 
and psychological resources and responses that can reduce or nullify the negative impact of identity threats, and 2) the impact of these and other features on the interpretive process that individuals engage in when faced with external identity threats. Future research in identity theory should address these factors and potentially incorporate them into the overall model of identityrelevant threats.

The above limitations suggest several promising directions for future research. First, in addition to longitudinal data, researchers should utilize data on highly stigmatized groups in the US such as Muslims and atheists (Edgell, Gerteis, and Hartmann 2006) to examine how forms of religious tension such as perceptions of television programming may be linked to mental health in these populations. Second, there may be important variations in the style and content of individuals' prayer and diversity of interpretation in scriptural reading (Baker 2008; Bartkowski 1996). Future research should assess how these variations may impact the extent to which these religious practices moderate the impact of negative media portrayal on mental health outcomes. Such research could help shed new light on how these moderators function. Third, researchers have used religious affiliation to examine religious tension and physical or overall health outcomes (e.g., Gardner, Sanborn, and Slattery 1995). Future research would be advanced by using multidimensional measures of religious tension with the media to assess specific mechanisms and how religious involvement moderates effects on mental health. Fourth, our results suggest that ongoing inquiry into subjective forms of religious stress, along with other mental health research on the negative effects of religion, may provide additional complexity and balance to studies on the beneficial effects of religion. This work may also help identify vulnerable populations. Fifth, qualitative research examining the interpretive process involved in the link between negative media portrayals, religious participation, and mental health will likely 
be particularly informative. Indeed, in-depth interviews gathering subjective accounts from individuals with differing levels of religious participation and ethnographic studies examining the availability, utilization, and content of religious narratives within specific religious communities may be essential for disentangling the social processes at play. These and other extensions to this work would deepen our understanding of the health-promoting and illnesscausing potential of religion in people's lives. More broadly, this study underscores the need for research on perceived violation of other things deemed sacred (e.g., cultural or political ideals) and links to mental health. 


\section{REFERENCES}

Acevedo, Gabriel A., Christopher G. Ellison, and Xiaohe Xu. 2014. "Is It Really Religion? Comparing the Main and Stress-Buffering Effects of Religious and Secular Civic Engagement on Psychological Distress.” Society and Mental Health 4(2):111-28.

Allport, Gordon W. 1950. The Individual and His Religion. New York: Macmillan.

Bader, Christopher David, Frederick Carson Mencken, and Joe Baker. 2010. Paranormal America Ghost Encounters, UFO Sightings, Bigfoot Hunts, and Other Curiosities in Religion and Culture. New York: New York University Press.

Bader, Christopher, F.Carson Mencken, and Paul Froese. 2007. “American Piety 2005: Content and Methods of the Baylor Religion Survey.” Journal for the Scientific Study of Religion 46(4):447-63.

Baker, Joseph O. 2008. "An Investigation of the Sociological Patterns of Prayer Frequency and Content.” Sociology of Religion 69(2):169-85.

Baker, Joseph O. and Buster G. Smith. 2009. "The Nones: Social Characteristics of the Religiously Unaffiliated.” Social Forces 87(3):1251-63.

Bartkowski, John. 1996. "Beyond Biblical Literalism and Inerrancy: Conservative Protestants and the Hermeneutic Interpretation of Scripture.” Sociology of Religion 57(3):259-72.

Beaujean, A.Alexander. 2014. Latent Variable Modeling Using R: A Step-by-Step Guide. New York: Routledge.

Berger, Peter L. 1967. The Sacred Canopy: Elements of a Sociological Theory of Religion. Garden City, N.Y: Doubleday.

Bierman, Alex. 2006. "Does Religion Buffer the Effects of Discrimination on Mental Health? Differing Effects by Race.” Journal for the Scientific Study of Religion 45(4):551-65.

Bradshaw, Matt and Christopher G. Ellison. 2010. "Financial Hardship and Psychological Distress: Exploring the Buffering Effects of Religion.” Social Science \& Medicine 71(1):196-204.

Bradshaw, Matt, Christopher G. Ellison, and Jack P. Marcum. 2010. "Attachment to God, Images of God, and Psychological Distress in a Nationwide Sample of Presbyterians." International Journal for the Psychology of Religion 20(2):130-47.

Burke, Peter J. 1991. “Identity Processes and Social Stress.” American Sociological Review 56(6):836-849.

Burke, Peter J. and Michael M. Harrod. 2005. “Too Much of a Good Thing?” Social Psychology Quarterly 68(4):359-74. 
Burke, Peter J. and Jan E. Stets. 2009. Identity Theory. New York: Oxford University Press.

Cast, Alicia D. and Peter J. Burke. 2002. “A Theory of Self-Esteem.” Social Forces 80(3):104168.

Collins, Randall. 2010. "The Micro-Sociology of Religion: Religious Practices, Collective and Individual.”

DiPrete, Thomas A., Andrew Gelman, Tyler McCormick, Teitler, and Tian Zheng. 2011. "Segregation in Social Networks Based on Acquaintanceship and Trust." American Journal of Sociology 116(4):1234-83.

Dougherty, Kevin D., Byron R. Johnson, and Edward C. Polson. 2007. "Recovering the Lost: Remeasuring U.S. Religious Affiliation.” Journal for the Scientific Study of Religion 46(4):483-99.

Douglas, Mary. 1966. Purity and Danger: An Analysis of Concepts of Pollution and Taboo. New York: Praeger.

Durkheim, Emile. 1912. The Elementary Forms of Religious Life. New York: Free Press.

Edgell, Penny, Joseph Gerteis, and Douglas Hartmann. 2006. “Atheists as 'Other’: Moral Boundaries and Cultural Membership in American Society.” American Sociological Review 71(2):211-34.

Edgell, Penny, Eric P. Tranby, and Darin M. Mather. 2013. "Profiles of Anticipated Support: Religion's Place in the Composition of Americans' Emotional Support Networks." Journal for the Scientific Study of Religion 52(2):293-308.

Ellison, Christopher G. 1991. "Religious Involvement and Subjective Well-Being.” Journal of Health and Social Behavior 32(1):80-99.

Ellison, Christopher G., Matt Bradshaw, Kevin J. Flannelly, and Kathleen C. Galek. 2014. "Prayer, Attachment to God, and Symptoms of Anxiety-Related Disorders among U.S. Adults." Sociology of Religion 75(2):208-33.

Ellison, Christopher G., Qijuan Fang, Kevin J. Flannelly, and Rebecca A. Steckler. 2013. "Spiritual Struggles and Mental Health: Exploring the Moderating Effects of Religious Identity." International Journal for the Psychology of Religion 23(3):214-229.

Ellison, Christopher G. and Linda K. George. 1994. "Religious Involvement, Social Ties, and Social Support in a Southeastern Community.” Journal for the Scientific Study of Religion 33(1):46-61.

Ellison, Christopher G. and Andrea K. Henderson. 2011. "Religion and Mental Health: Through the Lens of the Stress Process." Pp. 11-44 in Toward a sociological theory of religion and health, Religion and the social order, edited by A. J. Blasi. Boston: Brill. 
Ellison, Christopher G., Neal M. Krause, Bryan C. Shepherd, and Mark A. Chaves. 2009. "Size, Conflict, and Opportunities for Interaction: Congregational Effects on Members’ Anticipated Support and Negative Interaction.” Journal for the Scientific Study of Religion 48(1):1-15.

Ellison, Christopher G. and Jinwoo Lee. 2010. "Spiritual Struggles and Psychological Distress: Is There a Dark Side of Religion?” Social Indicators Research 98(3):501-17.

Ellison, Christopher G., Marc A. Musick, and Andrea K. Henderson. 2008. “Balm in Gilead: Racism, Religious Involvement, and Psychological Distress Among African-American Adults.” Journal for the Scientific Study of Religion 47(2):291-309.

Emerson, Michael O. and David Hartman. 2006. “The Rise of Religious Fundamentalism.” Annual Review of Sociology 32(1):127-44.

Exline, Julie Juola. 2002. "Stumbling Blocks on the Religious Road: Fractured Relationships, Nagging Vices, and the Inner Struggle to Believe.” Psychological Inquiry 13(3):182-89.

Foldnes, Njål and Knut Arne Hagtvet. 2014. "The Choice of Product Indicators in Latent Variable Interaction Models: Post Hoc Analyses.” Psychological Methods 19(3):444-57.

Foley, Daniel Patrick. 1988. “Eleven Interpretations of Personal Suffering.” Journal of Religion and Health 27(4):321-28.

Folkman, Susan and Judith Tedlie Moskowitz. 2004. “Coping: Pitfalls and Promise.” Annual Review of Psychology 55(1):745-74.

Freud, Sigmund. 1928. The Future of an Illusion. London: Hogarth Press.

Froese, Paul. 2016. On Purpose: How We Create the Meaning of Life. New York: Oxford University Press.

Froese, Paul and Christopher D. Bader. 2010. America's Four Gods: What We Say About God and What That Says About Us. New York: Oxford University Press.

Gardner, John W., Jill S. Sanborn, and Martha L. Slattery. 1995. "Behavioral Factors Explaining the Low Risk for Cervical Carcinoma in Utah Mormon Women.” Epidemiology 6(2):187-189.

Glassner, Barry. 2010. Culture of Fear. 2nd ed. New York: Basic Books.

Henderson, Andrea K. and Christopher G. Ellison. 2014. "My Body Is a Temple: Eating Disturbances, Religious Involvement, and Mental Health Among Young Adult Women.” Journal of Religion and Health 1-23.

Hill, Terrence D. and Ryon J. Cobb. 2011. “Religious Involvement and Religious Struggles.” Pp. 239-60 in Toward a Sociological Theory of Religion and Health, edited by A. Blasi. Boston: Brill. 
Hoover, Stewart M. 2005. “Media.” Pp. 305-19 in Handbook of Religion and Social Institutions, edited by H. R. Ebaugh. Boston, MA: Springer.

Hu, Li-tze and Peter M. Bentler. 1999. "Cutoff Criteria for Fit Indexes in Covariance Structure Analysis: Conventional Criteria versus New Alternatives.” Structural Equation Modeling: A Multidisciplinary Journal 6(1):1-55.

Iannaccone, Lawrence R. 1994. "Why Strict Churches Are Strong.” American Journal of Sociology 99(5):1180-1211.

Idler, Ellen L. 1995. “Religion, Health, and Nonphysical Senses of Self.” Social Forces 74(2):683-704.

Idler, Ellen L., Carol Hogue, and Karen Scheib. 2010. “Under the Umbrella of Religion and Health: What Makes Religion and Public Health Research Different from Religion and Medicine Research?”

Inglehart, R. 2010. “Faith and Freedom: Traditional and Modern Ways to Happiness.” Pp. 351397 in International differences in well-being, edited by E. Diener, J. F. Helliwell, and D. Kahneman. New York, NY: Oxford University Press.

Kerr, Peter A. 2003. "The Framing of Fundamentalist Christians: Network Television News, 1980-2000.” Journal of Media and Religion 2(4):203-235.

Koenig, Harold G., Dana E. King, and Verna Benner Carson. 2012. Handbook of Religion and Health. 2nd ed. New York, NY: Oxford University Press.

Krause, Neal. 2008. “The Social Foundation of Religious Meaning in Life.” Research on Aging 30(4):395-427.

Krause, Neal and Christopher G. Ellison. 2003. "Forgiveness by God, Forgiveness of Others, and Psychological Well-Being in Late Life.” Journal for the Scientific Study of Religion 42(1):77-93.

Krause, Neal and Christopher G. Ellison. 2009. "The Doubting Process: A Longitudinal Study of the Precipitants and Consequences of Religious Doubt in Older Adults.” Journal for the Scientific Study of Religion 48(2):293-312.

Krause, Neal and Keith M. Wulff. 2004. "Religious Doubt and Health: Exploring the Potential Dark Side of Religion.” Sociology of Religion 65(1):35-56.

Lim, Chaeyoon. 2015. "Religion and Subjective Well-Being Across Religious Traditions: Evidence from 1.3 Million Americans.” Journal for the Scientific Study of Religion 54(4):684-701.

Lin, Guan-Chyun, Zhonglin Wen, Herbert W. Marsh, and Huey-Shyan Lin. 2010. "Structural Equation Models of Latent Interactions: Clarification of Orthogonalizing and Double- 
Mean-Centering Strategies.” Structural Equation Modeling: A Multidisciplinary Journal 17(3):374-91.

Link, Bruce G. and Jo C. Phelan. 2001. “Conceptualizing Stigma.” Annual Review of Sociology 27(1):363-85.

Marsh, Herbert W., Zhonglin Wen, and Kit-Tai Hau. 2004. "Structural Equation Models of Latent Interactions: Evaluation of Alternative Estimation Strategies and Indicator Construction.” Psychological Methods 9(3):275-300.

Nooney, Jennifer and Eric Woodrum. 2002. "Religious Coping and Church-Based Social Support as Predictors of Mental Health Outcomes: Testing a Conceptual Model.” Journal for the Scientific Study of Religion 41(2):359-68.

Pargament, Kenneth I., Harold G. Koenig, and Lisa M. Perez. 2000. "The Many Methods of Religious Coping: Development and Initial Validation of the RCOPE.” Journal of Clinical Psychology 56(4):519-43.

Pargament, Kenneth I., Harold G. Koenig, Nalini Tarakeshwar, and June Hahn. 2004. "Religious Coping Methods as Predictors of Psychological, Physical and Spiritual Outcomes among Medically Ill Elderly Patients: A Two-Year Longitudinal Study.” Journal of Health Psychology 9(6):713-730.

Pearce, Lisa D. and Shannon N. Davis. 2006. "Religion Work-Family Gender Ideology and Fertility.” Presented at the Population Association of America 2006 Annual Meeting Los Angeles California March 30-April 12006.

Pearlin, Leonard I. 1989. “The Sociological Study of Stress.” Journal of Health and Social Behavior 30(3):241-256.

Pieper, Joseph and Marinus Van Uden. 2005. Religion and Coping in Mental Health Care. New York: Rodopi.

Pollner, M. 1989. “Divine Relations, Social Relations, and Well-Being.” Journal of Health and Social Behavior 30(1):92-104.

Rowatt, Wade and Lee A. Kirkpatrick. 2002. "Two Dimensions of Attachment to God and Their Relation to Affect, Religiosity, and Personality Constructs.” Journal for the Scientific Study of Religion 41(4):637-651.

Schieman, S. 2008. "The Education-Contingent Association Between Religiosity and Health: The Differential Effects of Self-Esteem and the Sense of Mastery.” Journal for the Scientific Study of Religion 47(4):710-724.

Schieman, Scott, Alex Bierman, and Christopher G. Ellison. 2010. "Religious Involvement, Beliefs About God, and the Sense of Mattering Among Older Adults.” Journal for the Scientific Study of Religion 49(3):517-535. 
Schieman, Scott, Alex Bierman, and Christopher G. Ellison. 2013. "Religion and Mental Health.” Pp. 457-478 in Handbook of the Sociology of Mental Health, edited by C. S. Aneshensel, J. C. Phelan, and A. Bierman. New York: Springer.

Sherkat, Darren E. 2014. Changing faith: the dynamics and consequences of Americans'shifting religious identities. New York: NYU Press.

Sivo, S. A., X. T. Fan, E. L. Witta, and J. T. Willse. 2006. “The Search For 'optimal' cutoff Properties: Fit Index Criteria in Structural Equation Modeling.” Journal of Experimental Education 74(3):267-88.

Smith, Christian, Michael Emerson, Sally Gallagher, Paul Kennedy, and David Sikkink. 1998. American Evangelicalism: Embattled and Thriving. Chicago: University of Chicago Press.

Stark, Rodney and Roger Finke. 2000. Acts of Faith: Explaining the Human Side of Religion. Berkeley: University of California Press.

Steensland, Brian, Jerry Z. Park, Lynn D. Robinson, W.Bradford Wilcox, and Robert D. Woodberry. 2000. "The Measure of American Religion: Toward Improving the State of the Art.” Social Forces 79(1):291-318.

Sternthal, Michelle J., David R. Williams, Marc A. Musick, and Anna C. Buck. 2012. "Religious Practices, Beliefs, and Mental Health: Variations across Ethnicity.” Ethnicity \& Health 17(1-2):171-85.

Stets, Jan E. and Peter J. Burke. 2014a. “Emotions and Identity Nonverification.” Social Psychology Quarterly 77(4):387-410.

Stets, Jan E. and Peter J. Burke. 2014b. “Self-Esteem and Identities.” Sociological Perspectives 57(4):409-33.

Stroope, Samuel. 2011. "How Culture Shapes Community: Bible Belief, Theological Unity, and a Sense of Belonging in Religious Congregations.” The Sociological Quarterly 52(4):568-592.

Stroope, Samuel, Scott Draper, and Andrew L. Whitehead. 2013. “Images of a Loving God and Sense of Meaning in Life.” Social Indicators Research 111(1):25-44.

Stryker, Sheldon. 1980. Symbolic Interactionism: A Social Structural Version. Menlo Park, Calif.: Benjamin/Cummings Pub. Co.

Stryker, Sheldon. 1987. "Identity Theory: Developments and Extensions.” Pp. 89-103 in Self and identity: Psychosocial perspectives, edited by K. Yardley and T. Honess. Oxford, UK: Wiley.

Stryker, Sheldon and Richard T. Serpe. 1982. "Commitment, Identity Salience, and Role Behavior: Theory and Research Example.” Pp. 199-218 in Personality, Roles, and Social 
Behavior, Springer Series in Social Psychology, edited by W. Ickes and E. S. Knowles. New York: Springer.

Thoits, Peggy A. 1983. "Multiple Identities and Psychological Well-Being: A Reformulation and Test of the Social Isolation Hypothesis.” American Sociological Review 48(2):174-87.

Thoits, Peggy A. 1992. "Identity Structures and Psychological Well-Being: Gender and Marital Status Comparisons.” Social Psychology Quarterly 55(3):236-56.

Thoits, Peggy A. 2012. "Role-Identity Salience, Purpose and Meaning in Life, and Well-Being among Volunteers.” Social Psychology Quarterly 75(4):360-84.

Thoits, Peggy A. 2013. “Self, Identity, Stress, and Mental Health.” Pp. 357-77 in Handbook of the Sociology of Mental Health, Handbooks of Sociology and Social Research, edited by C. S. Aneshensel, J. C. Phelan, and A. Bierman. Springer Netherlands.

Thomson, Robert A., Jerry Z. Park, and Diana Kendall. 2014. “Religious Exclusivism and Perceived Anti-Religious Media Bias.” San Francisco, CA.

Uecker, Jeremy E., Christopher G. Ellison, Kevin J. Flannelly, and Amy M. Burdette. 2015. "Belief in Human Sinfulness, Belief in Experiencing Divine Forgiveness, and Psychiatric Symptoms.” Review of Religious Research 58:1-26.

Uecker, Jeremy E. and Charles E. Stokes. 2008. “Early Marriage in the United States.” Journal of Marriage and Family 70(4):835-46.

Vargas, Nicholas and Matthew T. Loveland. 2011. "Befriending the 'Other': Patterns of Social Ties between the Religious and Non-Religious.” Sociological Perspectives 54(4):713731.

Walker, Mark H. and Freda B. Lynn. 2013. “The Embedded Self A Social Networks Approach to Identity Theory.” Social Psychology Quarterly 76(2):151-79.

Wheaton, Blair. 1985. "Models for the Stress-Buffering Functions of Coping Resources." Journal of Health and Social Behavior 26(4):352-364.

Winship, Christopher and Larry Radbill. 1994. "Sampling Weights and Regression Analysis.” Sociological Methods \& Research 23(2):230-57.

Wuthnow, Robert. 1987. Meaning and Moral Order: Explorations in Cultural Analysis. Berkeley: University of California Press.

Zinbarg, Richard E., William Revelle, Iftah Yovel, and Wen Li. 2005. “Cronbach's A, Revelle's B, and Mcdonald's $\omega \mathrm{H}$ : Their Relations with Each Other and Two Alternative Conceptualizations of Reliability.” Psychometrika 70(1):123-33. 


\section{Dependent Variables}

General Anxiety Disorder (Q) Over the past month, how often have you: (never, rarely, sometimes, often and very often)

(1) Felt nervous, anxious, or on edge

(2) Not been able to stop or control worrying

(3) Worried too much about different things

Social Anxiety (Q) Over the past month, how often have you: (never, rarely, sometimes, often and very often)

(1) Feared that you might do something to embarrass yours elf in a social situation

(2) Endured intense anxiety in social or performance situations

(3) Became anxious doing things because people were watching

General Mental Health

Problems

(Q) Overall Health: (none, 1 - 10 days, 11 - 20 days, 21 - 29 days, all 30 days)

(1) Now thinking about your mental health, which includes stress, depression, and problems with emotions, for how many days during the past 30 days was your mental health not good?

(2) During the past 30 days, for about how many days have you felt sad, blue, or depressed?

(3) During the past 30 days, for about how many days have you felt worried, tense, or anxious?

\section{Independent Variable}

Media Portrayal (Q) When watching television, have your religious beliefs ever been offended by negative comments made on: (Yes, No)
(1) Crime dramas
(2) Medical dramas
(3) Reality TV shows
(4) Comedic "news" shows
(5) Comedic sitcoms
(6) Cable news shows
(7) Evening news programs

Source: BRS Wave 3 (2010). 
Table 2: Descriptive Statistics for Study Variables

\begin{tabular}{|c|c|c|c|}
\hline & Range & Mean/\% & Std Dev \\
\hline Age & $0-108$ & 55.87 & 16.24 \\
\hline White & 0,1 & 94.83 & \\
\hline Female & 0,1 & 54.13 & \\
\hline Urban & 0,1 & 16.91 & \\
\hline South & 0,1 & 35.18 & \\
\hline Married & 0,1 & 65.53 & \\
\hline Employed & 0,1 & 47.19 & \\
\hline Liberal Political Ideology & $1-7$ & 3.57 & 1.66 \\
\hline \multicolumn{4}{|l|}{ Income } \\
\hline$<\$ 10 \mathrm{k}$ & 0,1 & 7.34 & \\
\hline$<\$ 20 \mathrm{k}$ & 0,1 & 8.67 & \\
\hline$<\$ 35 \mathrm{k}$ & 0,1 & 14.23 & \\
\hline$<\$ 50 \mathrm{k}$ & 0,1 & 17.20 & \\
\hline$<\$ 100 \mathrm{k}$ & 0,1 & 31.63 & \\
\hline$<\$ 150 \mathrm{k}$ & 0,1 & 12.84 & \\
\hline$>\$ 150 \mathrm{k}$ & 0,1 & 8.10 & \\
\hline College Education & 0,1 & 37.69 & \\
\hline Hours of TV/day & $1-5$ & 2.25 & 0.82 \\
\hline \multicolumn{4}{|l|}{ RELTRAD } \\
\hline Evangelical & 0,1 & 32.61 & \\
\hline Mainline & 0,1 & 25.09 & \\
\hline Catholic & 0,1 & 24.48 & \\
\hline Jewish & 0,1 & 1.62 & \\
\hline Other & 0,1 & 5.60 & \\
\hline None & 0,1 & 10.23 & \\
\hline Private Religiosity & $-1.37-1.3$ & 0.00 & 0.90 \\
\hline Public Religiosity & $-3.9-4.1$ & 0.00 & 2.98 \\
\hline
\end{tabular}

Source: BRS wave 3 (2010) 
Figure 1: Structural Equation Models
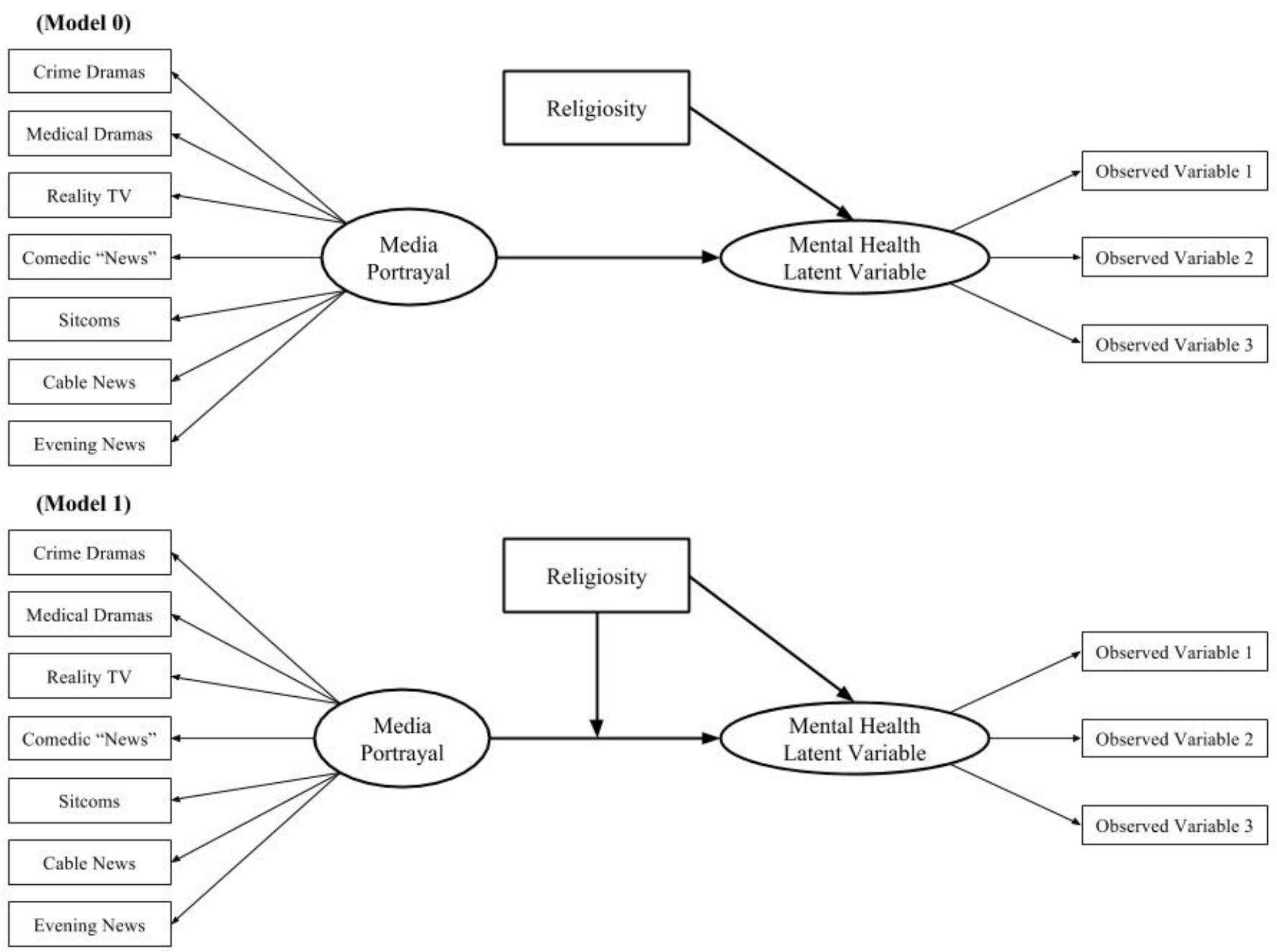

Note: Example of model structure - see Table l for specific information about each mental health latent variable; All models include the following controls: age, race, sex, urbanicity, southern residence, marital status, employment status, political ideology, income, college education, average hours viewing TV daily, and RELTRAD. 
Table 3: Structural Equation Models of Mental Health, Public Religiosity, Media Portrayal, and Covariates

\begin{tabular}{|c|c|c|c|c|c|c|c|c|c|c|c|c|c|c|c|c|c|c|}
\hline & \multicolumn{6}{|c|}{ Gen. Anxiety Disorder } & \multicolumn{6}{|c|}{ Social Anxiety } & \multicolumn{6}{|c|}{ Gen. Mental Health Problems } \\
\hline & \multicolumn{3}{|c|}{ Model 1} & \multicolumn{3}{|c|}{ Model 2} & \multicolumn{3}{|c|}{ Model 3} & \multicolumn{3}{|c|}{ Model 4} & \multicolumn{3}{|c|}{ Model 5} & \multicolumn{3}{|c|}{ Model 6} \\
\hline & $b$ & $\beta$ & SE & $b$ & $\beta$ & $\mathrm{SE}$ & $b$ & $\beta$ & $\mathrm{SE}$ & $b$ & $\beta$ & $\mathrm{SE}$ & $b$ & $\beta$ & $\mathrm{SE}$ & $b$ & $\beta$ & SE \\
\hline Age & $-0.008 * * *$ & -0.124 & 0.002 & $-0.008 * * *$ & -0.124 & 0.002 & $-0.007 * * *$ & -0.114 & 0.002 & $-0.007 * * *$ & -0.114 & 0.002 & $-0.014 * * *$ & -0.215 & 0.002 & $-0.014 * * *$ & -0.215 & 0.002 \\
\hline White & 0.218 & 0.045 & 0.144 & 0.218 & 0.045 & 0.145 & 0.119 & 0.025 & 0.153 & 0.119 & 0.025 & 0.153 & 0.032 & 0.007 & 0.144 & 0.032 & 0.007 & 0.145 \\
\hline Female & $0.198 * * *$ & 0.093 & 0.059 & $0.199 * * *$ & 0.093 & 0.059 & 0.017 & 0.008 & 0.064 & 0.017 & 0.008 & 0.064 & $0.138 *$ & 0.064 & 0.063 & $0.138 *$ & 0.064 & 0.063 \\
\hline Urban & -0.121 & -0.043 & 0.077 & -0.122 & -0.430 & 0.077 & $-0.206 *$ & -0.074 & 0.087 & $-0.206 *$ & -0.074 & 0.087 & -0.125 & -0.043 & 0.084 & -0.126 & -0.043 & 0.085 \\
\hline South & -0.113 & -0.051 & 0.061 & -0.113 & -0.051 & 0.062 & $-0.147 *$ & -0.067 & 0.066 & $-0.147 *$ & -0.067 & 0.066 & $-0.173 * *$ & -0.076 & 0.065 & $-0.173 * *$ & -0.076 & 0.065 \\
\hline Married & -0.009 & -0.004 & 0.067 & -0.009 & -0.004 & 0.068 & -0.096 & -0.044 & 0.074 & -0.096 & -0.044 & 0.074 & -0.069 & -0.030 & 0.071 & -0.069 & -0.030 & 0.071 \\
\hline Employed & -0.017 & -0.008 & 0.066 & -0.018 & -0.008 & 0.067 & -0.028 & -0.013 & 0.072 & -0.028 & -0.013 & 0.072 & -0.081 & -0.037 & 0.071 & -0.082 & -0.037 & 0.071 \\
\hline Liberal Political Ideology & 0.034 & 0.053 & 0.019 & 0.034 & 0.053 & 0.019 & 0.022 & 0.035 & 0.020 & 0.022 & 0.035 & 0.020 & $0.057 * *$ & 0.087 & 0.020 & $0.057 * *$ & 0.087 & 0.020 \\
\hline \multicolumn{19}{|l|}{ Income $^{a}$} \\
\hline$<\$ 10,000$ & $0.446 * * *$ & 0.109 & 0.134 & $0.448 * *$ & 0.109 & 0.134 & 0.232 & 0.058 & 0.144 & 0.232 & 0.058 & 0.144 & $0.351 * *$ & 0.084 & 0.134 & $0.352 * *$ & 0.084 & 0.135 \\
\hline$\$ 10,000-\$ 20,000$ & $0.353 * *$ & 0.094 & 0.128 & $0.355 * *$ & 0.094 & 0.129 & $0.333 *$ & 0.090 & 0.138 & $0.333 *$ & 0.090 & 0.139 & $0.296 *$ & 0.077 & 0.142 & $0.297 *$ & 0.077 & 0.142 \\
\hline$\$ 20,000-\$ 35,000$ & 0.035 & 0.012 & 0.107 & 0.035 & 0.012 & 0.108 & -0.004 & -0.001 & 0.115 & -0.004 & -0.001 & 0.115 & 0.025 & 0.008 & 0.112 & 0.025 & 0.008 & 0.113 \\
\hline$\$ 50,000-\$ 100,000$ & -0.173 & -0.075 & 0.092 & -0.173 & -0.075 & 0.092 & -0.113 & -0.050 & 0.099 & -0.113 & -0.050 & 0.099 & -0.185 & -0.079 & 0.097 & -0.185 & -0.079 & 0.098 \\
\hline$\$ 100,000-\$ 150,000$ & -0.194 & -0.061 & 0.116 & -0.195 & -0.061 & 0.117 & -0.218 & -0.070 & 0.129 & -0.218 & -0.070 & 0.129 & -0.161 & -0.050 & 0.122 & -0.162 & -0.050 & 0.122 \\
\hline$>\$ 150,000$ & $-0.309 *$ & -0.080 & 0.133 & $-0.310 *$ & -0.080 & 0.134 & $-0.342 *$ & -0.089 & 0.152 & $-0.342 *$ & -0.089 & 0.152 & -0.256 & -0.065 & 0.139 & -0.256 & -0.065 & 0.139 \\
\hline College Education & -0.096 & -0.044 & 0.066 & -0.096 & -0.044 & 0.067 & -0.105 & -0.049 & 0.072 & -0.105 & -0.049 & 0.072 & -0.016 & -0.007 & 0.070 & -0.016 & -0.007 & 0.071 \\
\hline Hours of TV/day & $0.086 *$ & 0.067 & 0.036 & $0.087 *$ & 0.067 & 0.037 & 0.078 & 0.061 & 0.042 & 0.078 & 0.061 & 0.042 & $0.113 * *$ & 0.086 & 0.039 & $0.114 * *$ & 0.086 & 0.039 \\
\hline \multicolumn{19}{|l|}{ RELTRAD $^{\mathrm{b}}$} \\
\hline Mainline & 0.010 & 0.004 & 0.077 & 0.010 & 0.004 & 0.077 & -0.023 & -0.009 & 0.084 & -0.023 & -0.009 & 0.084 & 0.145 & 0.058 & 0.081 & 0.146 & 0.058 & 0.082 \\
\hline Catholic & -0.024 & -0.010 & 0.078 & -0.025 & -0.010 & 0.078 & 0.020 & 0.008 & 0.082 & 0.020 & 0.008 & 0.082 & 0.157 & 0.062 & 0.083 & 0.157 & 0.062 & 0.083 \\
\hline Jewish & 0.074 & 0.009 & 0.242 & 0.075 & 0.009 & 0.243 & 0.214 & 0.026 & 0.267 & 0.215 & 0.026 & 0.267 & 0.127 & 0.015 & 0.251 & 0.128 & 0.015 & 0.252 \\
\hline Other & -0.125 & -0.028 & 0.125 & -0.125 & -0.028 & 0.126 & -0.009 & -0.002 & 0.132 & -0.009 & -0.002 & 0.132 & 0.073 & 0.016 & 0.125 & 0.073 & 0.016 & 0.125 \\
\hline None & $-0.229 *$ & -0.065 & 0.116 & $-0.230 *$ & -0.065 & 0.117 & -0.192 & -0.055 & 0.124 & -0.192 & -0.055 & 0.124 & 0.001 & 0.000 & 0.118 & 0.001 & 0.000 & 0.119 \\
\hline Media Portrayal (A) & 0.035 & 0.033 & 0.035 & 0.068 & 0.063 & 0.039 & $0.072 *$ & 0.069 & 0.036 & $0.084 *$ & 0.080 & 0.040 & 0.049 & 0.046 & 0.035 & $0.077 *$ & 0.071 & 0.039 \\
\hline Public Religiosity $(B)$ & $-0.038 * * *$ & -0.106 & 0.011 & $-0.038 * * *$ & -0.106 & 0.011 & -0.017 & -0.048 & 0.013 & -0.017 & -0.048 & 0.013 & $-0.043 * * *$ & -0.119 & 0.012 & $-0.044 * * *$ & -0.119 & 0.011 \\
\hline $\mathrm{A} \times \mathrm{B}$ & & - & & $-0.103 * *$ & -0.097 & 0.032 & & - & & -0.038 & -0.037 & 0.033 & & - & & $-0.085 * *$ & -0.078 & 0.032 \\
\hline \multicolumn{19}{|l|}{ Model 0 Fit Indices } \\
\hline Mc & \multicolumn{6}{|c|}{0.966} & \multicolumn{6}{|c|}{0.843} & \\
\hline CFI & \multicolumn{6}{|c|}{0.995} & \multicolumn{6}{|c|}{0.971} & \multicolumn{6}{|c|}{0.995} \\
\hline TLI & \multicolumn{6}{|c|}{0.994} & \multicolumn{6}{|c|}{0.967} & \multicolumn{6}{|c|}{0.994} \\
\hline RMSEA (95\% CI) & \multicolumn{6}{|c|}{$0.017(0.013-0.021)$} & & & $.038(0$. & $6-0.041)$ & & & & & $.018(0.0$ & $4-0.021)$ & & \\
\hline SRMR & & & & & & & & & & & & & & & & & & \\
\hline$R^{2}$ & & .112 & & & 0.121 & & & 0.082 & & & 0.083 & & & .145 & & & 0.15 & \\
\hline
\end{tabular}

Source : BRS Wave 3 (2010); ${ }^{\mathrm{a}}=\$ 35,000-\$ 50,000$ is comparison group; ${ }^{\mathrm{b}}=$ evangelical is comparison group; $*<p .05 ; * *<p .01 ; * * *<p .001$ 


\begin{tabular}{|c|c|c|c|c|c|c|c|c|c|c|c|c|c|c|c|c|c|c|}
\hline & \multicolumn{6}{|c|}{ Gen. Anxiety Disorder } & \multicolumn{6}{|c|}{ Social Anxiety } & \multicolumn{6}{|c|}{ Gen. Mental Health Problems } \\
\hline & \multicolumn{3}{|c|}{ Model 1} & \multicolumn{3}{|c|}{ Model 2} & \multicolumn{3}{|c|}{ Model 3} & \multicolumn{3}{|c|}{ Model 4} & \multicolumn{3}{|c|}{ Model 5} & \multicolumn{3}{|c|}{ Model 6} \\
\hline & $b$ & $\beta$ & $\mathrm{SE}$ & $b$ & $\beta$ & $\mathrm{SE}$ & $b$ & $\beta$ & SE & $b$ & $\beta$ & SE & $b$ & $\beta$ & SE & $b$ & $\beta$ & SE \\
\hline Age & $-0.008 * * *$ & -0.122 & 0.002 & $-0.008 * * *$ & -0.122 & 0.002 & $-0.111 * * *$ & -0.111 & 0.002 & $-0.007 * * *$ & -0.111 & 0.002 & $-0.014 * * *$ & -0.214 & 0.002 & $-0.014 * * *$ & -0.214 & 0.002 \\
\hline White & 0.253 & 0.052 & 0.143 & 0.254 & 0.052 & 0.143 & 0.019 & 0.019 & 0.151 & 0.091 & 0.019 & 0.151 & 0.054 & 0.011 & 0.145 & 0.055 & 0.011 & 0.146 \\
\hline Female & $0.205 * * *$ & 0.096 & 0.060 & $0.206 * * *$ & 0.096 & 0.060 & 0.018 & 0.018 & 0.066 & 0.037 & 0.018 & 0.066 & 0.118 & 0.054 & 0.063 & 0.118 & 0.054 & 0.064 \\
\hline Urban & -0.113 & -0.040 & 0.076 & -0.113 & -0.040 & 0.077 & $-0.075 *$ & -0.075 & 0.087 & $-0.210 *$ & -0.075 & 0.088 & -0.124 & -0.043 & 0.084 & -0.125 & -0.043 & 0.085 \\
\hline South & -0.105 & -0.047 & 0.061 & -0.105 & -0.047 & 0.062 & $-0.061 *$ & -0.061 & 0.067 & $-0.133 *$ & -0.061 & 0.067 & $-0.179 * *$ & -0.079 & 0.066 & $-0.180 * *$ & -0.079 & 0.066 \\
\hline Married & 0.002 & 0.001 & 0.067 & 0.002 & 0.001 & 0.067 & -0.045 & -0.045 & 0.072 & -0.100 & -0.045 & 0.072 & -0.063 & -0.028 & 0.071 & -0.063 & -0.028 & 0.072 \\
\hline Liberal Political Ideology & 0.032 & 0.049 & 0.019 & 0.032 & 0.049 & 0.019 & 0.027 & 0.027 & 0.021 & 0.017 & 0.027 & 0.021 & $0.062 * *$ & 0.095 & 0.020 & $0.063 * *$ & 0.095 & 0.021 \\
\hline \multicolumn{19}{|l|}{ Income $^{\mathrm{a}}$} \\
\hline$<\$ 10,000$ & $0.468 * * *$ & 0.114 & 0.136 & $0.471 * * *$ & 0.114 & 0.137 & 0.061 & 0.061 & 0.148 & 0.246 & 0.061 & 0.148 & $0.382 * *$ & 0.092 & 0.131 & $0.384 * *$ & 0.092 & 0.132 \\
\hline$\$ 10,000-\$ 20,000$ & $0.361 * *$ & 0.096 & 0.122 & $0.363 * *$ & 0.096 & 0.123 & $0.095 * *$ & 0.095 & 0.133 & $0.355 * *$ & 0.095 & 0.134 & $0.306 *$ & 0.079 & 0.131 & $0.308 *$ & 0.080 & 0.131 \\
\hline$\$ 20,000-\$ 35,000$ & 0.031 & 0.010 & 0.107 & 0.031 & 0.010 & 0.108 & -0.005 & -0.005 & 0.116 & -0.015 & -0.005 & 0.117 & 0.016 & 0.005 & 0.107 & 0.016 & 0.005 & 0.108 \\
\hline$\$ 50,000-\$ 100,000$ & -0.169 & -0.074 & 0.092 & -0.170 & -0.074 & 0.093 & -0.050 & -0.050 & 0.102 & -0.114 & -0.050 & 0.102 & -0.175 & -0.075 & 0.094 & -0.176 & -0.075 & 0.094 \\
\hline$\$ 100,000-\$ 150,000$ & -0.197 & -0.062 & 0.115 & -0.198 & -0.062 & 0.116 & -0.065 & -0.065 & 0.134 & -0.205 & -0.065 & 0.135 & -0.136 & -0.042 & 0.120 & -0.136 & -0.042 & 0.121 \\
\hline$>\$ 150,000$ & $-0.302 *$ & -0.078 & 0.138 & $-0.303 *$ & -0.078 & 0.139 & $-0.093 *$ & -0.093 & 0.156 & $-0.355 *$ & -0.093 & 0.157 & -0.235 & -0.059 & 0.140 & -0.236 & -0.059 & 0.141 \\
\hline \multicolumn{19}{|l|}{ RELTRAD $^{\mathrm{b}}$} \\
\hline Mainline & 0.015 & 0.006 & 0.077 & 0.015 & 0.006 & 0.078 & -0.010 & -0.010 & 0.083 & -0.023 & -0.010 & 0.084 & 0.161 & 0.065 & 0.083 & 0.162 & 0.065 & 0.084 \\
\hline Catholic & -0.029 & -0.012 & 0.077 & -0.029 & -0.012 & 0.077 & 0.003 & 0.003 & 0.083 & 0.007 & 0.003 & 0.084 & $0.172 *$ & 0.068 & 0.082 & $0.173 *$ & 0.068 & 0.082 \\
\hline Jewish & 0.035 & 0.004 & 0.251 & 0.035 & 0.004 & 0.252 & 0.026 & 0.026 & 0.263 & 0.218 & 0.026 & 0.263 & 0.146 & 0.017 & 0.258 & 0.147 & 0.017 & 0.260 \\
\hline Other & -0.128 & -0.028 & 0.126 & -0.129 & -0.028 & 0.126 & -0.002 & -0.002 & 0.132 & -0.008 & -0.002 & 0.132 & 0.078 & 0.017 & 0.125 & 0.079 & 0.017 & 0.126 \\
\hline None & $-0.233 *$ & -0.066 & 0.116 & $-0.234 *$ & -0.066 & 0.117 & -0.064 & -0.064 & 0.127 & $-0.223+$ & -0.064 & 0.127 & 0.041 & 0.011 & 0.119 & 0.041 & 0.011 & 0.119 \\
\hline Public Religiosity & $-0.037 * *$ & -0.104 & 0.014 & $-0.037 * *$ & -0.104 & 0.014 & -0.006 & -0.006 & 0.016 & -0.002 & -0.006 & 0.016 & $-0.057 * * *$ & -0.158 & 0.014 & $-0.058 * * *$ & -0.158 & 0.014 \\
\hline Media Portrayal (A) & 0.042 & 0.039 & 0.033 & $0.081 *$ & 0.076 & 0.036 & $0.083 *$ & 0.083 & 0.036 & $0.114 * *$ & 0.109 & 0.040 & 0.039 & 0.036 & 0.036 & $0.082 *$ & 0.075 & 0.041 \\
\hline Private Religiosity $(B)$ & -0.010 & -0.009 & 0.045 & -0.010 & -0.009 & 0.046 & -0.069 & -0.069 & 0.052 & -0.080 & -0.069 & 0.052 & 0.084 & 0.071 & 0.047 & 0.085 & 0.071 & 0.048 \\
\hline A $\times$ B & & - & & $-0.111 * * *$ & -0.104 & 0.031 & & - & & $-0.075 *$ & -0.072 & 0.034 & & - & & $-0.120 * * *$ & -0.110 & 0.031 \\
\hline \multicolumn{19}{|l|}{ Model 0 Fit Indices } \\
\hline Mc & \multicolumn{6}{|c|}{0.9} & \multicolumn{6}{|c|}{0.893} & \multicolumn{6}{|c|}{0.901} \\
\hline CFI & \multicolumn{6}{|c|}{0.98} & \multicolumn{6}{|c|}{0.975} & \multicolumn{6}{|c|}{0.986} \\
\hline TLI & \multicolumn{6}{|c|}{0.977} & \multicolumn{6}{|c|}{0.971} & \multicolumn{6}{|c|}{0.984} \\
\hline RMSEA (95\% CI) & & & $.030(0$. & $7-0.033)$ & & & & & $.031(0$. & $8-0.034)$ & & & & & $.029(0$. & $7-0.032)$ & & \\
\hline SRMR & & & & & & & & & & & & & & & & & & \\
\hline
\end{tabular}


Figure 2: Interplay between negative media portrayal of religion, public religiosity, and mental health

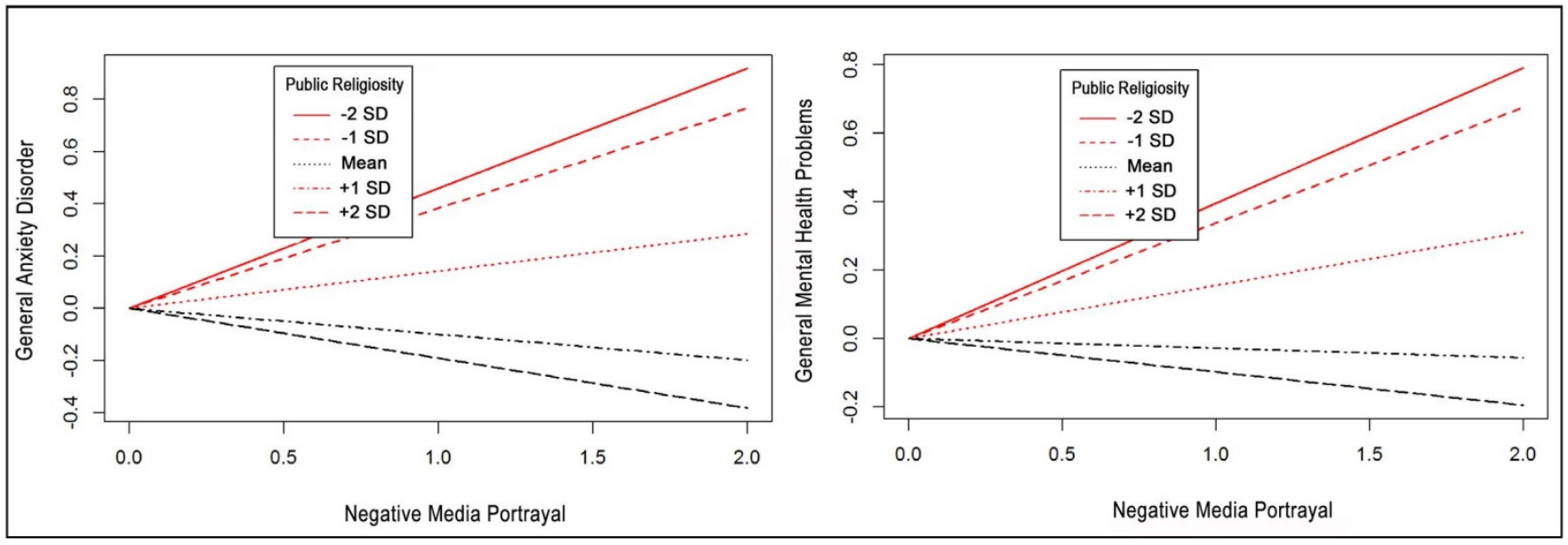

Note - In cases where $+/-2$ standard deviations lie outside the observed range of the data, maximum and minimum observed values are used instead.

Figure 3: Interplay between negative media portrayal of religion, private religiosity, and mental health

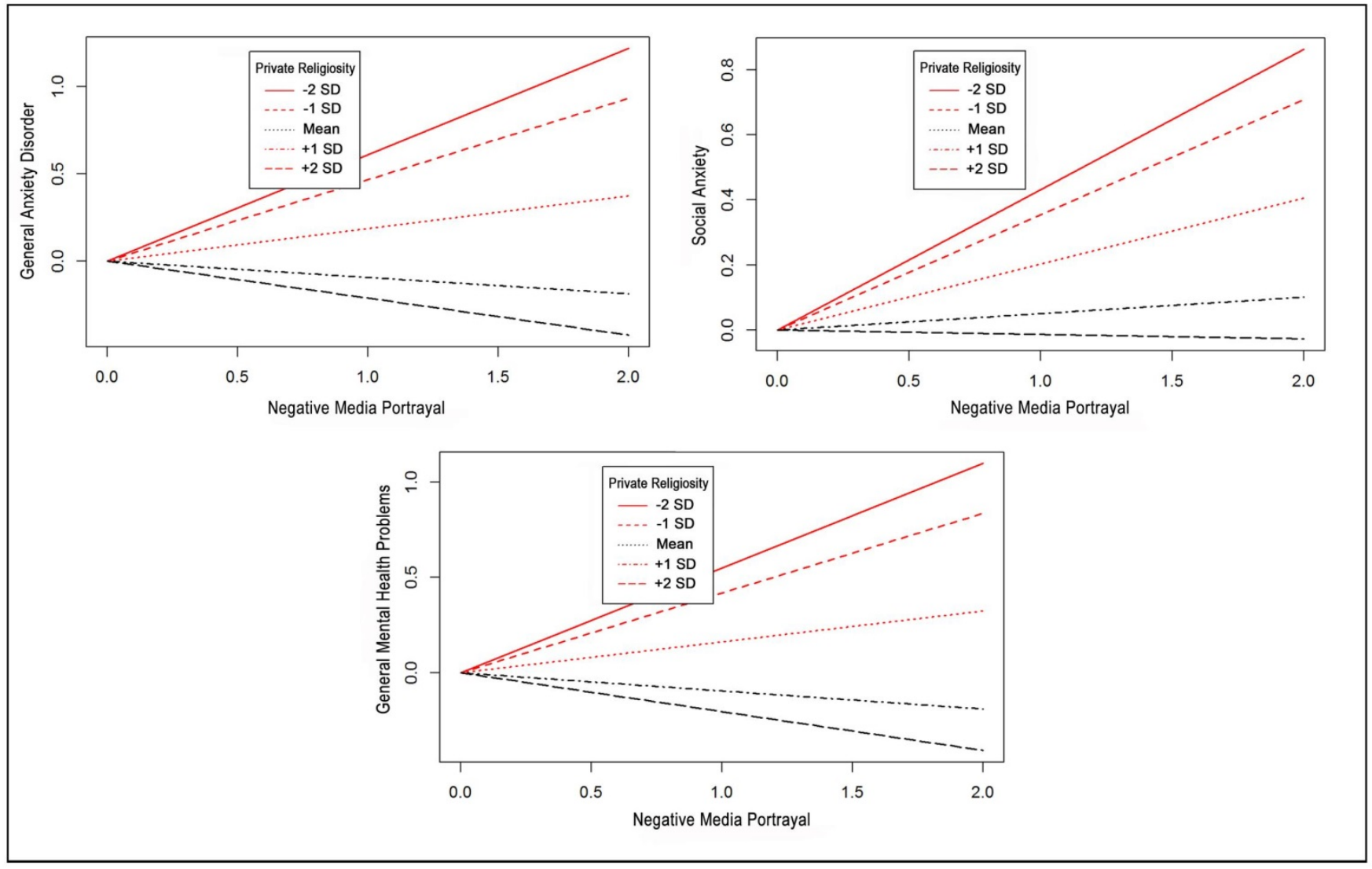

Note - In cases where +/- 2 standard deviations lie outside the observed range of the data, maximum and minimum observed values are used instead. 